\title{
Platinum- and iron-doubly promoted tungstated zirconia catalyst for $n$-butane isomerization reaction
}

\author{
She-Tin Wong ${ }^{a}$, Tao Li ${ }^{a}$, Soofin Cheng ${ }^{a}$, Jyh-Fu Lee ${ }^{b}$, Chung-Yuan Mou ${ }^{\text {a,c,* }}$ \\ ${ }^{a}$ Department of Chemistry, National Taiwan University, Taipei 106, Taiwan \\ ${ }^{\mathrm{b}}$ National Synchrotron Radiation Research Center, Hsinchu, Taiwan \\ ${ }^{\mathrm{c}}$ Center of Condensed Matter Science, National Taiwan University, Taipei 106, Taiwan
}

Received 29 May 2005; received in revised form 30 July 2005; accepted 4 August 2005

Available online 17 October 2005

\begin{abstract}
The catalysis of $n$-butane isomerization over iron-promoted tungstated zirconia $\left(\mathrm{F}_{1.2} \mathrm{WZ}\right)$ and platinum-iron-promoted tungstated zirconia $\left(\mathrm{P} / \mathrm{F}_{1.2} \mathrm{WZ}\right)$ catalysts was studied and correlated to the catalyst characterization results. In the singly promoted $\mathrm{F}_{1.2} \mathrm{WZ}_{\mathrm{Z}}$ catalyst, we suggest that the iron species promotes the $n$-butane isomerization reaction through a redox effect. The formation of W-O-Fe linkages optimized the surface reduction of $\mathrm{WO}_{x}$, thereby facilitating the formation of Brønsted acid sites necessary for the generation of carbenium ion. In addition, $\mathrm{Fe}^{3+}$ itself can also act as a redox site. In the case of the doubly promoted $\mathrm{P} / \mathrm{F}_{1.2} \mathrm{WZ}$ catalyst, its catalytic activity is much higher than the sum of the singly promoted $\mathrm{P} / \mathrm{WZ}$ and $\mathrm{F}_{1.2} \mathrm{WZ}$ catalysts. The exceptionally high activity of $\mathrm{P} / \mathrm{F}_{1.2} \mathrm{WZ}$ catalyst in $n$-butane isomerization reaction is explained by a cooperative effect. The diffusion of activated $n$-butane species stabilized by iron promoter to the Brønsted acid sites created by platinum promoter will be improved as both promoters are in close proximity to each other. The interaction between iron promoter and $n$ butane or its activated species is shown by the influence of iron on the propane selectivity of the reaction. In addition, the close proximity of platinum and iron promoters in $\mathrm{P} / \mathrm{F}_{1.2} \mathrm{WZ}$ catalyst is shown by TPR. The location and nature of iron promoter on WZ were also characterized. Results revealed that the iron promoter is located on the surface of $\mathrm{F}_{1.2} \mathrm{WZ}$ catalyst. XANES, EXAFS, and EPR studies suggest that the iron promoter exists as highly dispersed $\mathrm{Fe}^{3+}$ species either bound to $\mathrm{WO}_{x}$ surface or located at the surface vacant sites of zirconia. In addition, EPR study indicates the presence of fine $\alpha-\mathrm{Fe}_{2} \mathrm{O}_{3}$ clusters on the surface of catalyst; the TPR peak at $421{ }^{\circ} \mathrm{C}$ is probably due to $\mathrm{Fe}-\mathrm{O}-\mathrm{Fe}$ of this species.
\end{abstract}

(C) 2005 Elsevier B.V. All rights reserved.

Keywords: Tungstated zirconia; Promoter; Platinum; Iron; $n$-Butane isomerization; EXAFS

\section{Introduction}

Many research groups have continued to study the properties of oxide-based strong acids in an attempt to replace the conventional acid catalysts such as liquid acids and halide-containing solids which have caused serious environmental concerns. Among strong solid acids, sulfated zirconia (SZ) and tungstated zirconia, $\mathrm{WO}_{x} / \mathrm{ZrO}_{2}$ (WZ), have shown promising catalytic behavior, and thus have received significant attention from the catalytic community. However, the long-term stability of the zirconia-supported

\footnotetext{
* Corresponding author. Fax: +88622366 0954.

E-mail address: cymou@ntu.edu.tw (C.-Y. Mou).
}

sulfate species in SZ has cast serious doubt on its applications. The alternative to SZ, the more stable WZ catalyst, has become increasingly important since its discovery by Hino and Arata [1]. Later, its strong acidic properties were also demonstrated by several authors with the isomerization reactions of normal alkanes such as butane [2], pentane [3,4], and hexane [5,6].

Kuba et al. [7] has proposed a non-catalytic redox process for the activation of $n$-pentane on WZ. This process involves a homolytic $\mathrm{C}-\mathrm{H}$ bond cleavage reaction on $\mathrm{WO}_{x}$, followed by one-electron transfer steps that yield surface $\mathrm{W}^{5+}$ ions, $\mathrm{OH}$ groups, and carbenium ions. Carbenium ion then acts as a chain carrier in the catalytic cycle of isomerization reaction. The carbenium ion could also act as an initiator for 
$\mathrm{C}-\mathrm{H}$ bond dissociation. Thus, the redox property of $\mathrm{W}^{6+}$ in $\mathrm{WO}_{x}$ is thought to play a crucial role in this initiation process of $n$-pentane isomerization reaction.

Since the catalytic activity of WZ is much lower than SZ, studies on WZ have widely focused on promoted catalysts. It is known that platinum is the best promoter for WZ in $n$ alkane isomerization reaction. The addition of platinum to WZ and hydrogen to the feed drastically improves the catalytic activity, stability and selectivity of iso-alkane. According to Barton et al. [8], hydrogen dissociates on platinum and facilitates the reduction of $\mathrm{WO}_{x}$ surfaces. The promotional effect of platinum may be two-fold: (a) creating Brønsted acid site on $\mathrm{WO}_{x}$, which is important for the formation of carbenium ion from alkene, leading subsequently to isomerization reaction and (b) enhancing the desorption of carbenium species as product, thus minimizing coke formation on $\mathrm{WO}_{x}$ surface.

When a second promoter such as iron, aluminum or gallium is present, the performance of this doubly promoted catalyst shows further improvement in catalytic activity, stability, and selectivity of iso-alkane over the singly promoted catalyst in $n$-alkane isomerization reaction. However, the role of the additional promoter still remains unresolved. Based on the characterization and catalytic results, several propositions have been made on the promotional effect of iron [9,10]: (a) ensemble effect, which stabilizes the platinum particles in a highly dispersed state; (b) diffusional effect, which facilitates the migration of activated molecules from platinum to the acid sites; (c) redox effect which enhances the reducibility of $\mathrm{W}^{6+}$ to $\mathrm{W}^{5+}$ in $\mathrm{WO}_{x}$. A promoter may promote the reaction through a combination of these effects. The action of gallium promoter may be explained by a redox effect and the aluminum promoter by an acidity effect [11-13].

In the study of iron-promoted WZ catalyst, the nature and location of iron promoter in the catalyst are of great interest. However, relatively few studies on the nature and location of iron promoter on WZ have been reported so far $[9,14]$. Nonetheless, there is a diversity of opinions. Tábora and Davis [15] suggested that iron did not substitute in the tetragonal structure but was present as nanometer-sized oxide clusters or rafts supported on zirconia. On the other hand, Yamamoto et al. [16] concluded that iron atoms form interstitial-type solid solution in the lattice of zirconia, that is, the atoms are located at the center of distorted oxygen octahedra. Okamoto et al. [17] reported on a study of metal oxide-support interaction in $\mathrm{Fe} / \mathrm{ZrO}_{2}$ catalysts by Mossbauer spectroscopy. Quite recently, Carrier et al. [18] has characterized the state of iron promoter in WZ catalysts and suggested that iron is occupying substitutional positions in the first surface layer of zirconia with a distorted octahedral coordination for $\mathrm{Fe}^{3+}$. Unfortunately, no catalytic data were provided to correlate the significance of their characterization results.

In this paper, we have prepared WZ catalysts promoted with platinum, iron, or both. They were studied by various characterization techniques and $n$-butane isomerization reaction. Our main purpose is to correlate the characterization and catalytic results. In addition, new catalytic evidences supporting the surface nature of iron promoter are provided. In order to locate the iron promoter on $\mathrm{WZ}$ and to understand its effect in $n$-butane isomerization reaction, we resort to various characterization techniques such as electron paramagnetic resonance (EPR) spectroscopy, extended X-ray absorption fine structure (EXAFS) and temperature-programmed reduction (TPR). EPR gives one the spin state of iron and tungsten. EXAFS spectra were taken at iron, tungsten, and zirconium centers in order to study the radial distribution of their neighbors. On the other hand, TPR can give us information on the nature of iron promoter and also on the strength of interaction between the promoter and its surrounding atoms.

\section{Experimental}

\subsection{Synthesis}

WZ catalysts were prepared by calcination of commercially available $\mathrm{WZ}$ precursor (MEL chemicals) at $800{ }^{\circ} \mathrm{C}$ in static air for $3 \mathrm{~h}$. The heating rate from room temperature to $800{ }^{\circ} \mathrm{C}$ was $5{ }^{\circ} \mathrm{C} \mathrm{min}{ }^{-1}$. Iron-promoted WZ (FWZ) catalyst was prepared by impregnating WZ precursor with ferric nitrate nonahydrate before calcination at $800{ }^{\circ} \mathrm{C}$. Platinumpromoted WZ (P/WZ) and FWZ (P/FWZ) catalysts were prepared by impregnating platinum tetrachloride on $\mathrm{WZ}$ and FWZ, respectively, followed by calcination at $500{ }^{\circ} \mathrm{C}$ in static air for $3 \mathrm{~h}$.

For comparison purposes, a separate catalyst was also prepared by simultaneous impregnation of ferric nitrate nonahydrate and platinum tetrachloride on $\mathrm{WZ}$, and then calcined at $500{ }^{\circ} \mathrm{C}$ in static air for $3 \mathrm{~h}$ to give $\mathrm{PF} / \mathrm{WZ}$ catalyst. It should be noted here that ferric nitrate nonahydrate was introduced on $\mathrm{WZ}$ in $\mathrm{PF} / \mathrm{WZ}$, whereas it was introduced on WZ precursor in P/FWZ.

\subsection{Characterization techniques}

The powder X-ray diffraction (XRD) patterns were recorded on powdered samples with a Scintag X1 diffractometer using $\mathrm{Cu} \mathrm{K} \alpha$ radiation. Nitrogen adsorption-desorption data were obtained at $-196{ }^{\circ} \mathrm{C}$ on a Micromeritics ASAP 2000 apparatus and were analyzed with BET equation for surface area determination. Elemental composition was analyzed with a simultaneous ICP-AES allied analytical system (Jarrel-Ash, Model ICAP 9000). Carbon analysis was done with a Heraeus VarioEL-III instrument.

A Brüker EMX EPR spectrometer (X-band) was employed to measure the electron paramagnetic resonance (EPR) spectra of the sample. The spectrometer is equipped with a variable temperature controller to record the 
spectrum at low temperatures. Typical spectrometer settings are: microwave frequency $9.53 \mathrm{GHz}$; microwave power $2 \mathrm{~mW}$; modulation amplitude $10 \mathrm{G}$; multiple scans were sometimes used to obtain a better signal/noise ratio. To record the EPR spectrum of hydrogen-reduced $\mathrm{F}_{1.2} \mathrm{WZ}$, we first reduced the fresh sample ex situ at $300{ }^{\circ} \mathrm{C}$ for $2 \mathrm{~h}$ in a flow system and then transferred it quickly to an EPR tube. After evacuation, the tube was sealed under an atmosphere of dry nitrogen.

The experiments on temperature-programmed oxidation (TPO) were carried out on a Du Pont 951 thermogravimetric analyzer. The analysis was monitored and controlled by an on-line computer system. The heating rate was $10{ }^{\circ} \mathrm{C} \mathrm{min}-1$ and the flow rate of air was $60 \mathrm{ml} \mathrm{min}{ }^{-1}$. Temperatureprogrammed reduction (TPR) experiments were done on a Micromeritics Autochem 2910 instrument. The heating rate was $10{ }^{\circ} \mathrm{C} \mathrm{min}^{-1}$ and the reducing gas was $10 \% \mathrm{H}_{2} / \mathrm{Ar}$ flowing at $50 \mathrm{ml} \mathrm{min}^{-1}$. The amount of catalyst used for all the TPR experiments was about $55 \mathrm{mg}$.

The studies on $\mathrm{Fe}-\mathrm{K}$-edge and $\mathrm{W}-\mathrm{L}_{\mathrm{II}, \mathrm{III}}$-edge X-ray absorption near edge structure (XANES) and extended Xray absorption fine structure (EXAFS) were performed at the National Synchrotron Radiation Research Center in Hsinchu, Taiwan. The electron storage ring was operated at about $1.5 \mathrm{GeV}$ with a ring current of about $200 \mathrm{~mA}$. The corresponding studies for $\mathrm{Zr}$-K-edge were performed at SPring8 in Japan. The electron storage ring was operated at $8 \mathrm{GeV}$ with a ring current of $75-100 \mathrm{~mA}$. All the experiments were done at room temperature. The resulting EXAFS data were analyzed with a standard FEFF6 program, as described in our previous paper [19].

\subsection{Catalytic study}

Catalytic study was carried out in a Pyrex microreactor flow system at atmospheric pressure. On-line product analysis was performed on a Shimadzu GC-14B gas chromatograph equipped with a flame ionization detector. The sample (about $0.52 \mathrm{~g}$ ) was pretreated for about $2 \mathrm{~h}$ at reaction temperature (usually $300{ }^{\circ} \mathrm{C}$ ) under a $10 \% \mathrm{H}_{2} / \mathrm{N}_{2}$ mixture flowing at about $60 \mathrm{ml} \mathrm{min}{ }^{-1}$. The reaction feed was a mixture of $n$-butane and hydrogen (volume ratio of

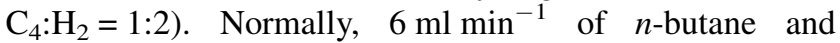
$12 \mathrm{ml} \mathrm{min}{ }^{-1}$ of $\mathrm{H}_{2}$ were used to give a total feed rate of $18 \mathrm{ml} \mathrm{min}{ }^{-1}$. Catalyst regeneration was done in situ under flowing air at $450{ }^{\circ} \mathrm{C}$ for $20 \mathrm{~h}$.

Catalytic performance was presented either in total conversion or turnover number (TON). Total conversion of $n$-butane is defined as the percentage of $n$-butane converted to hydrocarbon products, and isobutane selectivity is defined as the percentage of isobutane in the observed product. These data were based on carbon number. From the conversion and feed rate of $n$-butane, TON can be calculated and results were expressed as the amount of $n$-butane (in $\mu \mathrm{mol}$ ) converted per second per gram of catalyst.

\section{Results}

\subsection{General characterization}

The catalysts contained 11-13 wt.\% W metal, and these loadings are close to the optimum loading for best performing catalysts in isomerization reaction $[3,8,20]$. When platinum is employed, its loading is fixed at 0.4 0.5 wt. \% Pt. For iron-promoted catalysts, two iron loadings were used $(0.3$ and $1.2 \mathrm{wt} . \% \mathrm{Fe})$ and they were indicated as subscripts in the catalyst notation. Structural determination of WZ by XRD showed that it contained primarily tetragonal zirconia. The peaks due to tungsten oxide were also observed at such high loadings of tungsten [13]. The surface areas of the catalysts are between 68 and $71 \mathrm{~m}^{2} \mathrm{~g}^{-1}$.

\subsection{Catalytic study}

Table 1 summarizes the initial catalytic performance, in turnover number (TON), of representative catalysts in the isomerization reaction of $n$-butane at $300{ }^{\circ} \mathrm{C}$. Steady state performance followed a similar trend. It is important to note that $\mathrm{F}_{1.2} \mathrm{WZ}$ has higher activity than WZ catalyst and that platinum is the best promoter so far. The doubly promoted $\mathrm{P} / \mathrm{F}_{1.2} \mathrm{WZ}$ catalyst is the best performing catalyst and its activity is even higher than the sum of each individually promoted catalyst. Interestingly, there is a distinct difference in activity between $\mathrm{P} / \mathrm{F}_{0.3} \mathrm{WZ}$ and $\mathrm{PF}_{0.3} /$ $\mathrm{WZ}: \mathrm{PF}_{0.3} / \mathrm{WZ}$ catalyst shows much lower activity than $\mathrm{P} /$ $\mathrm{F}_{0.3} \mathrm{WZ}$.

We have also analyzed the cracking product of this reaction for catalysts shown in Table 1 . We found that the amount of propane in the reaction product increased when iron promoter is present on $\mathrm{WZ}$ catalyst. The relative molar yield of $\mathrm{CH}_{4}: \mathrm{C}_{2} \mathrm{H}_{6}: \mathrm{C}_{3} \mathrm{H}_{8}$ varies with iron content as shown in Table 1.

Fig. 1 compares the activity profiles of $\mathrm{F}_{1.2} \mathrm{WZ}$ catalyst in $n$-butane isomerization reaction after three repeated catalytic cycles. The profiles for fresh $\mathrm{P} / \mathrm{WZ}$ and $\mathrm{P} /$ $\mathrm{F}_{1.2} \mathrm{WZ}$ catalysts are also included for comparison and

Table 1

Catalytic performance of some selected catalysts in $n$-butane isomerization reaction

\begin{tabular}{llll}
\hline Catalysts $^{\mathrm{a}}$ & $\begin{array}{l}\mathrm{TON}^{\mathrm{b}, \mathrm{c}} \\
\left(\mu \mathrm{mol} \mathrm{g}^{-1} \mathrm{~s}^{-1}\right)\end{array}$ & Selectivity $^{\mathrm{b}, \mathrm{d}}(\%)$ & $\begin{array}{l}\mathrm{CH}_{4}: \mathrm{C}_{2} \mathrm{H}_{6}: \mathrm{C}_{3} \mathrm{H}_{8} \\
(\text { molar ratio) }\end{array}$ \\
\hline $\mathrm{WZ}$ & 0.10 & 87.6 & - \\
$\mathrm{F}_{1.2} \mathrm{WZ}$ & 0.20 & 85.9 & - \\
$\mathrm{P} / \mathrm{WZ}$ & 0.70 & 94.5 & $1.0: 1.0: 1.4$ \\
$\mathrm{P} / \mathrm{F}_{0.3} \mathrm{WZ}$ & 0.86 & 93.9 & $1.0: 1.0: 1.5$ \\
$\mathrm{PF}_{0.3} / \mathrm{WZ}$ & 0.19 & 92.5 & - \\
$\mathrm{P} / \mathrm{F}_{1.2} \mathrm{WZ}$ & 1.53 & 95.8 & $1.0: 1.1: 2.2$ \\
\hline
\end{tabular}

\footnotetext{
${ }^{a}$ Fresh catalysts; their notations are described in Section 2.

${ }^{\text {b }}$ Data taken after 5 min on stream at $300{ }^{\circ} \mathrm{C}$.

c Turnover number, as described in Section 2.

${ }^{d}$ Selectivity of isobutane.
} 


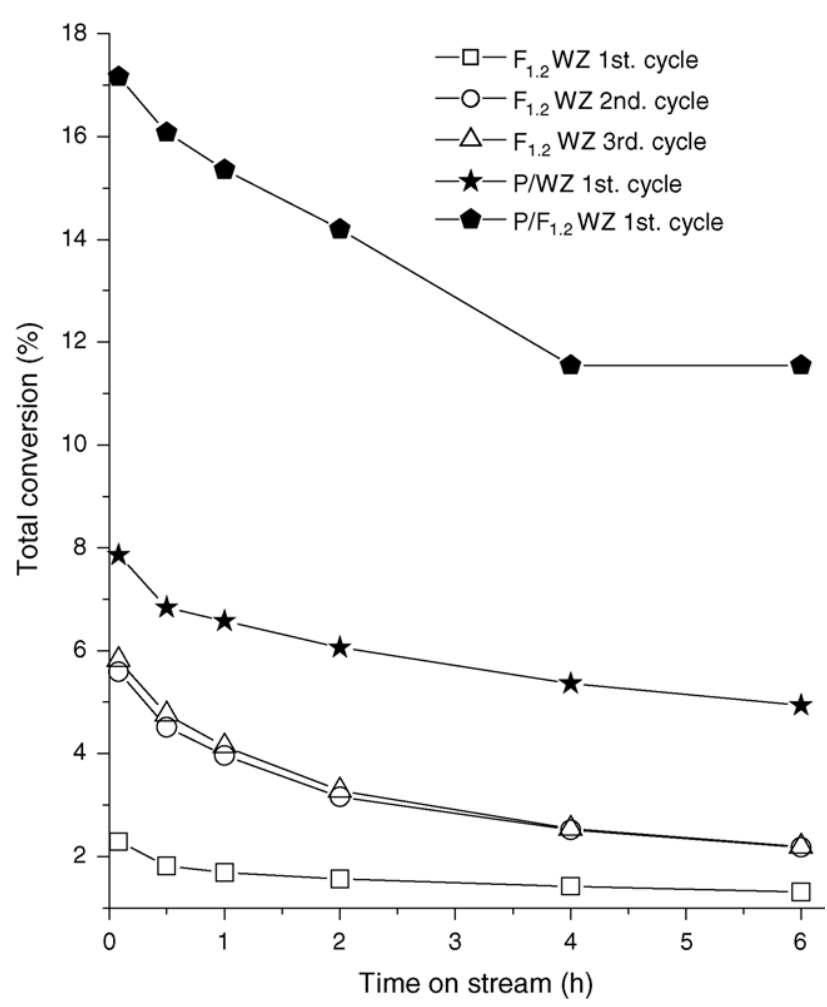

Fig. 1. Activity profiles of $\mathrm{F}_{1.2} \mathrm{WZ}, \mathrm{P} / \mathrm{WZ}$, and $\mathrm{P} / \mathrm{F}_{1.2} \mathrm{WZ}$ catalysts at $300{ }^{\circ} \mathrm{C}$ and volume ratio of $n$-butane to hydrogen is 1:2.

one can see that they have higher catalytic activities. An interesting observation is the drastic increase in activity for the second catalytic cycle relative to the first. On the other hand, the second and third cycles do not show such discrepancy in activity. We found that this activity jump is higher in $\mathrm{F}_{1.2} \mathrm{WZ}$ catalyst $(144 \%)$ than in $\mathrm{WZ}$ catalyst $(60 \%)$.

\subsection{TPO study}

In order to find out the degree of coking in catalytic reaction, we compare the TPO profiles of $\mathrm{P} / \mathrm{WZ}$ and $\mathrm{P} /$ $\mathrm{F}_{1.2} \mathrm{WZ}$ catalysts after $n$-butane isomerization reaction at $350{ }^{\circ} \mathrm{C}$ (Fig. 2). From the weight loss stages of both catalysts, we can see that most of the coke formed during the reaction can be burnt off before $500{ }^{\circ} \mathrm{C}(\sim 0.5 \mathrm{wt} . \%)$. However, distinct differences were also observed between these two catalysts. The profile of $\mathrm{P} / \mathrm{F}_{1.2} \mathrm{WZ}$ catalyst reaches a plateau at $\sim 450{ }^{\circ} \mathrm{C}$ and is followed by a weight gain stage, as opposed to continuous weight loss in the case of P/WZ.

\subsection{TPR study}

We next investigated the redox properties of the catalyst by temperature-programmed reduction (TPR). Fig. 3 compares the reduction behavior of both platinum-free and platinum-promoted $\mathrm{WZ}$ and $\mathrm{F}_{1.2} \mathrm{WZ}$ catalysts. All profiles showed a broad and intense peak centered at $760-800{ }^{\circ} \mathrm{C}$

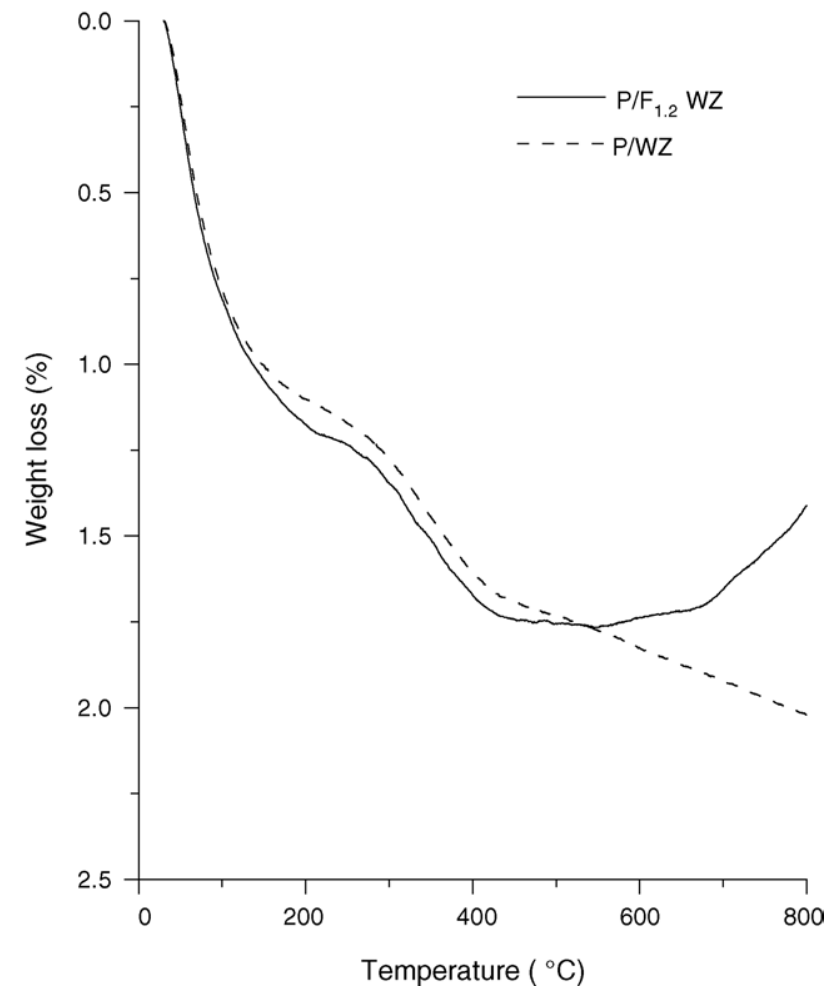

Fig. 2. TPO profiles of used $\mathrm{P} / \mathrm{WZ}$ and $\mathrm{P} / \mathrm{F}_{1.2} \mathrm{WZ}$ catalysts.

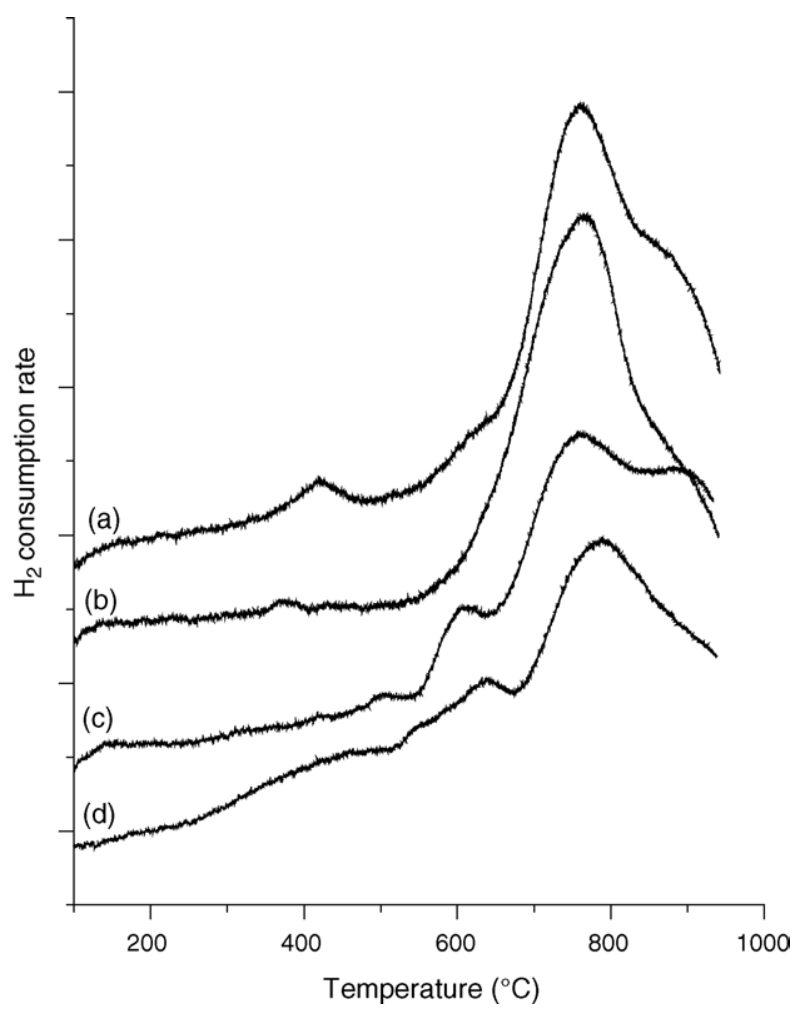

Fig. 3. TPR profiles of (a) $\mathrm{F}_{1.2} \mathrm{WZ}$, (b) WZ, (c) $\mathrm{P} / \mathrm{F}_{1.2} \mathrm{WZ}$, and (d) $\mathrm{P} / \mathrm{WZ}$ catalysts. 
due to the reduction of $\mathrm{WO}_{x}$ supported on zirconia [8]. The influence of promoter on the profile of $\mathrm{WZ}$ is described below:

(i) The effect of iron promoter on $\mathrm{WZ}$ can be seen by comparing the reduction profiles of $\mathrm{WZ}$ and $\mathrm{F}_{1.2} \mathrm{WZ}$ catalysts. Three reduction peaks can be seen at 421, $\sim 640$, and $\sim 850{ }^{\circ} \mathrm{C}$ on $\mathrm{F}_{1.2} \mathrm{WZ}$ (Fig. 3a). However, only a very small peak is observed in $\mathrm{WZ}$ at $383{ }^{\circ} \mathrm{C}$ (Fig. 3b), which may be due to the presence of a small amount of $\mathrm{Fe}^{3+}$ impurities in the sample.

(ii) The effect of platinum promoter on $\mathrm{WZ}$ can be seen by comparing the reduction profiles of P/WZ (Fig. 3d) and $\mathrm{WZ}$ catalysts. In the case of $\mathrm{P} / \mathrm{WZ}$, reduction of $\mathrm{WZ}$ starts at a much lower temperature than WZ. Continuous uptake of hydrogen begins even at $\sim 200{ }^{\circ} \mathrm{C}$. This observation is consistent with the idea that platinum helps in the reduction of $\mathrm{WO}_{x}$ by generating spillover hydrogen at room temperature [21]. At low temperatures, $\mathrm{WO}_{x}$ supported on zirconia can undergo slight reduction by delocalizing net negative charge over several $\mathrm{W}$ atoms. Further reduction of $\mathrm{WO}_{x}$ in $\mathrm{P} / \mathrm{WZ}$ catalyst appeared at $651{ }^{\circ} \mathrm{C}$ besides the loss at $800{ }^{\circ} \mathrm{C}$.

(iii) The effect of iron promoter on $\mathrm{P} / \mathrm{WZ}$ catalyst is examined by comparing the reduction profiles of $\mathrm{P} /$ $\mathrm{F}_{1.2} \mathrm{WZ}$ (Fig. 3c) and P/WZ catalysts. The uptake of hydrogen in the low temperature region of $\mathrm{P} / \mathrm{F}_{1.2} \mathrm{WZ}$ is not as high as that of $\mathrm{P} / \mathrm{WZ}$. This phenomenon indicates that there is some interaction between platinum and iron promoters in $\mathrm{P} / \mathrm{F}_{1.2} \mathrm{WZ}$. Another indication of such interaction is the disappearance of the peak at $421{ }^{\circ} \mathrm{C}$ seen in $\mathrm{F}_{1.2} \mathrm{WZ}$ catalyst. This kind of interaction seems to have an effect on the hydrogen chemisorption and/or dissociation properties of platinum.

We should mention here that no distinct peak due to platinum reduction was observed in our platinum-loaded catalysts. Platinum reduction usually occurs at a temperature between 100 and $200{ }^{\circ} \mathrm{C}$ [6]. Possibly, its reduction temperature is well below $100{ }^{\circ} \mathrm{C}$ in our case and therefore was not detected.

\subsection{EPR study}

We next focus on the effect of iron on the electronic state in $\mathrm{F}_{1.2} \mathrm{WZ}$ by using EPR technique. Fig. 4 shows the EPR spectra of $\mathrm{F}_{1.2} \mathrm{WZ}$ before and after reduction with hydrogen at $300{ }^{\circ} \mathrm{C}$ for $2 \mathrm{~h}$. In Fig. 4a, two strong EPR signals appeared at $g_{\perp} \sim 4.26$ (signal A) and 2.04 (signal B). Although the sample has been exposed briefly to air oxidation during the sample transfer process, the reduced species can still be identified. In the expanded spectra (Fig. 4b), two additional signals $\left(g_{\perp}=1.89\right.$ for $\mathrm{C}$ and 1.96 for D) are also prominent. The latter two signals are not observed in the spectrum of the sample before reduction.
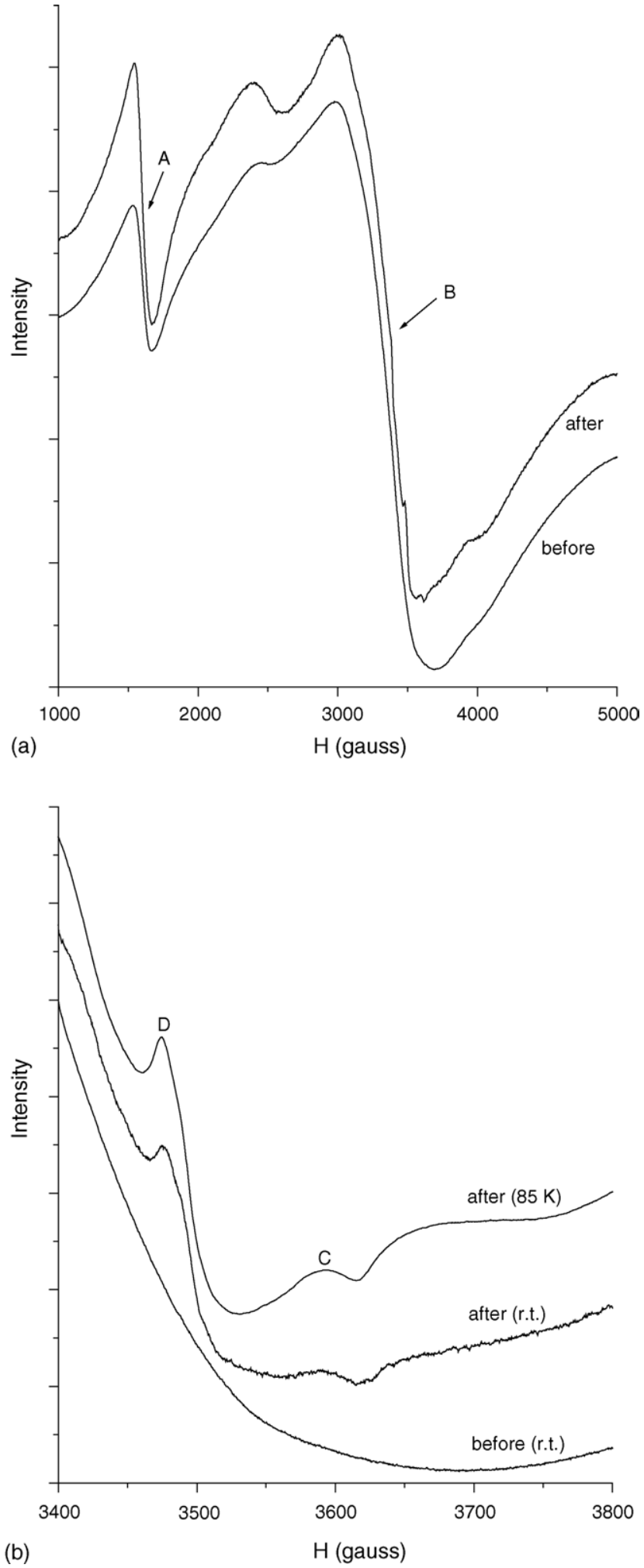

Fig. 4. (a) EPR spectrum of $\mathrm{F}_{1.2} \mathrm{WZ}$ catalyst before and after hydrogen reduction at $300{ }^{\circ} \mathrm{C}$ for $2 \mathrm{~h}$ (recorded at room temperature). (b) Expanded EPR spectrum of $\mathrm{F}_{1.2} \mathrm{WZ}$ catalyst before and after hydrogen reduction at $300{ }^{\circ} \mathrm{C}$ for $2 \mathrm{~h}$. Bracketed values indicate spectral recording temperatures. 


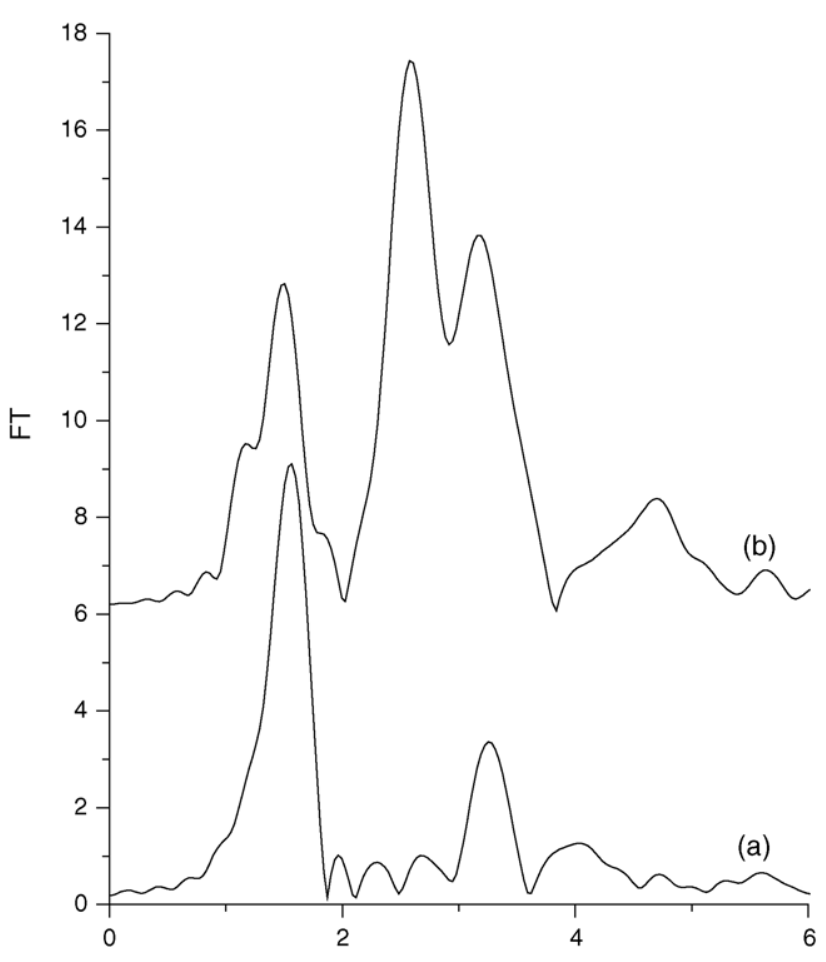

(a)

$\mathrm{R} \AA$

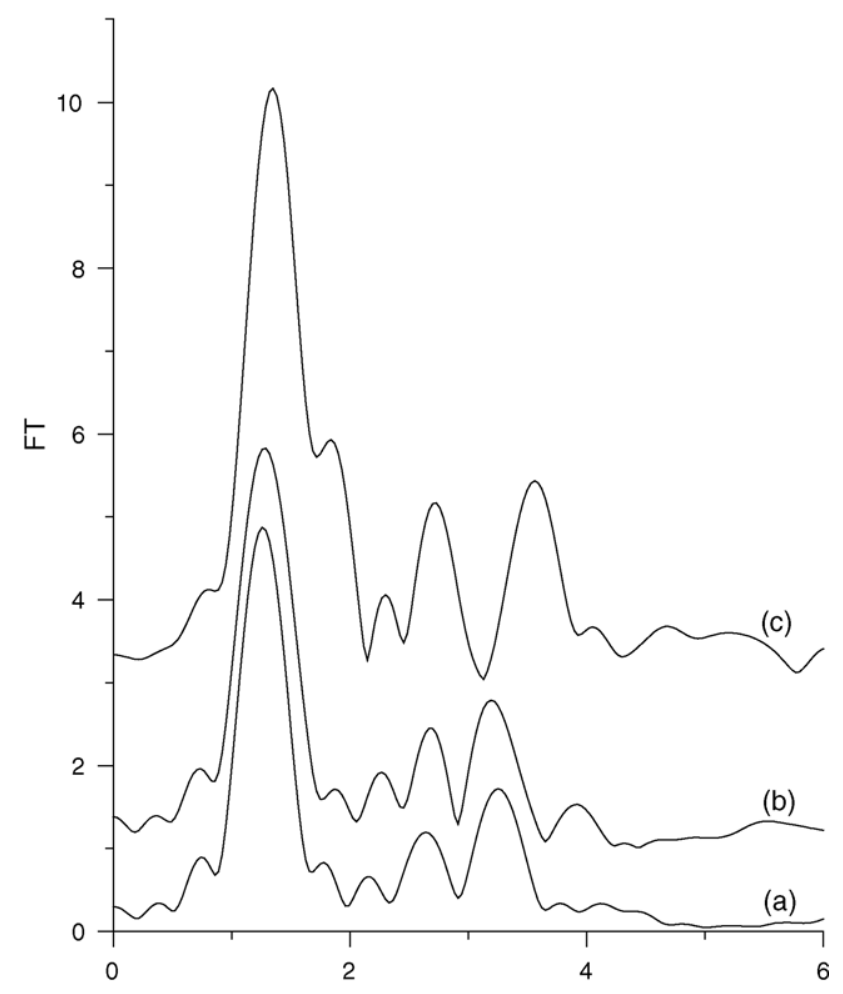

(b)

$R(\AA ̊)$

Fig. 5. (a) Fe-K-edge EXAFS RDFs of (a) $\mathrm{F}_{1.2} \mathrm{WZ}$ and (b) $\alpha-\mathrm{Fe}_{2} \mathrm{O}_{3}$. (b) $\mathrm{W}-$ $\mathrm{L}_{\mathrm{II}, \mathrm{III}}$-edge EXAFS RDFs of (a) WZ, (b) $\mathrm{F}_{1.2} \mathrm{WZ}$, and (c) $\mathrm{WO}_{3}$.
Another interesting observation is the increased proportion of signal A after this reduction/oxidation process.

\subsection{XANES and EXAFS studies}

In our XANES study, the Fe-K-edge absorption energy of $\mathrm{F}_{1.2} \mathrm{WZ}$ catalyst was determined from the first derivative of its X-ray absorption spectrum. The absorption edge energy for $1 \mathrm{~s} \rightarrow 4 \mathrm{p}$ transition was found to occur at $7127 \mathrm{eV}$ and is the same as $\alpha-\mathrm{Fe}_{2} \mathrm{O}_{3}$ standard. The same energy value was also reported for other $\mathrm{Fe}_{2} \mathrm{O}_{3}$-containing compounds [22]. This result confirms that the iron promoter in $\mathrm{F}_{1.2} \mathrm{WZ}$ catalyst exists in the $\mathrm{Fe}^{3+}$ state after calcination at $800{ }^{\circ} \mathrm{C}$.

We have also measured the EXAFS spectrum of our $\mathrm{F}_{1.2} \mathrm{WZ}$ catalyst at the absorption edge of $\mathrm{Fe}, \mathrm{W}$ and $\mathrm{Zr}$ so that the coordination environment around these centers can be understood. The important observations from these studies are described below:

(i) Fig. 5a compares the Fe-K-edge EXAFS RDF plots of $\mathrm{F}_{1.2} \mathrm{WZ}$ and bulk $\alpha-\mathrm{Fe}_{2} \mathrm{O}_{3}$. The first and second peaks in the $\mathrm{Fe}-\mathrm{O}-\mathrm{Fe}$ region of $\alpha-\mathrm{Fe}_{2} \mathrm{O}_{3}$ correspond to edge- and vertex-sharing $\mathrm{Fe}-\mathrm{O}-\mathrm{Fe}$, respectively. The $\mathrm{F}_{1.2} \mathrm{WZ}$ plot has two main peaks at about 1.6 and $3.3 \AA$ (not phaseshift corrected), and have been assigned to $\mathrm{Fe}-\mathrm{O}$ and $\mathrm{Fe}-$ $\mathrm{O}-\mathrm{Zr}$ bondings, respectively $[16,18,23]$. The small peak at $2.67 \AA$ may be due to $\mathrm{Fe}_{2} \mathrm{O}_{3}$. A shoulder at $2.7 \AA$ in the EXAFS spectrum of Carrier et al. [18] was also assigned to $\mathrm{Fe}_{2} \mathrm{O}_{3}$ clusters. Furthermore, the peak near $4 \AA$ could be due to $\mathrm{Fe}-\mathrm{O}-\mathrm{W}$, but its broadness indicates contribution from other materials also.

(ii) Fig. 5b compares the $\mathrm{W}-\mathrm{L}_{\mathrm{II}, \mathrm{III}}$-edge EXAFS RDF plots of $\mathrm{WZ}, \mathrm{F}_{1.2} \mathrm{WZ}$, and bulk $\mathrm{WO}_{3}$. Generally, the spectral feature of $\mathrm{WO}_{x}$ in $\mathrm{WZ}$ is similar to bulk $\mathrm{WO}_{3}$ except for a significant shift in the bond distance of the last peak. This peak corresponds to the $\mathrm{W}-\mathrm{O}-\mathrm{W}$ bond distance [24], and the peak shift is reasonably attributed to the interaction between $\mathrm{WO}_{x}$ and the zirconia support. Most importantly, an additional peak (W-O-Fe) appeared at a distance of nearly $4 \AA$ (not phase-shift corrected) in $\mathrm{F}_{1.2} \mathrm{WZ}$ and this is not found in WZ. Also, no broadening of the $\mathrm{W}-\mathrm{O}-\mathrm{W}$ peak was observed in $\mathrm{F}_{1.2} \mathrm{WZ}$ relative to $\mathrm{WZ}$.

(iii) The $\mathrm{Zr}$-K-edge EXAFS RDF plots of $\mathrm{F}_{1.2} \mathrm{WZ}$ and $\mathrm{WZ}$ are very similar (figure not shown). With reference to $\mathrm{WZ}$, no broadening of the $\mathrm{Zr}-\mathrm{O}-\mathrm{Zr}$ peak at $3.2 \AA$ (not phase-shift corrected) was observed in $\mathrm{F}_{1.2} \mathrm{WZ}$.

\section{Discussion}

\subsection{Possible reaction pathways and effect of promoters in $n$-butane isomerization reaction over $W Z$}

Butane isomerization over WZ can be viewed as a surface chain reaction comprising initiation, propagation, and 
termination steps [25]. In this paper, we are interested in the initiation process, which may be promoted by metals. We will not discuss the termination due to hydride transfer or coking. Many reaction mechanisms have been proposed for the initiation and propagation processes. The bimolecular mechanism shown below is a simplified version of that used to describe $n$-butane isomerization over $\mathrm{H}$ mordenites [26]:

$$
\begin{aligned}
& n-\mathrm{C}_{4} \mathrm{H}_{10} \rightarrow \mathrm{C}_{4} \mathrm{H}_{9}++\mathrm{H}^{-} \\
& \mathrm{C}_{4} \mathrm{H}_{9}{ }^{+} \rightarrow \mathrm{C}_{4} \mathrm{H}_{8}+\mathrm{H}^{+} \\
& \mathrm{H}^{+}+\mathrm{H}^{-} \rightarrow \mathrm{H}_{2} \\
& \mathrm{C}_{4} \mathrm{H}_{8}+\mathrm{H}^{+} \rightarrow \mathrm{C}_{4} \mathrm{H}_{9}{ }^{+} \\
& \mathrm{C}_{4} \mathrm{H}_{9}{ }^{+}+\mathrm{C}_{4} \mathrm{H}_{8} \rightarrow \mathrm{C}_{8} \mathrm{H}_{17}+\rightarrow i-\mathrm{C}_{4} \mathrm{H}_{10}
\end{aligned}
$$

We should mention that the initiation process for $n$-butane (Eq. (1)) is still a matter of speculation, however, either a hydride abstraction process (Eq. (1)) or protonation on the $\mathrm{C}_{4} \mathrm{H}_{8}$ (as impurity) will give $\mathrm{C}_{4} \mathrm{H}_{9}{ }^{+}$. As we have described in the introduction section, the Brønsted acid site (Eq. (4)) is created by a slight hydrogen reduction of $\mathrm{WO}_{x}$ through delocalization of negative charge in $\mathrm{WO}_{x}$ domains. This reduction process may be facilitated by platinum promoter. In addition, platinum will also increase the rate of hydrogenolysis of reactant and product. It is also possible that iron promoter itself plays the role of redox site for the generation of $\mathrm{H}^{+}$on $\mathrm{WO}_{x}$ surface (see Section 4.3).

We shall discuss our catalytic and characterization results in correlation to this simple mechanism; some new ideas on promotional effect are also presented. Of course, the detailed mechanism will be more complex; we need here, however, only the simple skeleton to identify the roles of promoters.

\subsection{General catalytic observation}

Generally, our catalytic data conform to the well-known promotional effect of both platinum and iron $[4,27]$. This is evident by comparing the isomerization activity of P/WZ or $\mathrm{F}_{1.2} \mathrm{WZ}$ with WZ. Surprisingly, Scheithauer et al. [14] found no promotional effect of manganese and iron on WZ. The authors ascribed this behavior to the loss of manganese and iron promoters via the formation of the respective tungstate. Interestingly, we have found that the activity of our doubly promoted catalyst ( $\mathrm{Pt}$ and $\mathrm{Fe}$ ) can change according to the method of catalyst preparation (Section 3.2). Here, the iron source is impregnated on $\mathrm{WZ}$ in $\mathrm{F}_{0.3} / \mathrm{WZ}$ and the iron source is bound to the hydroxide precursor of $\mathrm{WZ}$ in $\mathrm{F}_{0.3} \mathrm{WZ}$. Therefore, it is reasonable to assume that the iron promoter in the latter case is more strongly anchored onto WZ surface than the former. Not surprisingly, $\mathrm{P} / \mathrm{F}_{0.3} \mathrm{WZ}$ has higher catalytic activity than $\mathrm{PF}_{0.3} / \mathrm{WZ}$ in $n$-butane isomerization reaction. This result showed that the presence of a minimal amount of weakly anchored iron promoter on the surface of a low surface area catalyst like $\mathrm{PF}_{0.3} / \mathrm{WZ}$ can lead to a lower catalytic activity. One possible explanation for this phenomenon is the formation of some alloy-like compound between iron and platinum during catalyst preparation or pretreatment stages. This finding demonstrates again how a minor variation of the preparation procedure of a catalyst can affect its catalytic performance.

\subsection{Promotional effect of iron}

Previously, Knözinger and coworkers have inferred that the promotional effect of $\mathrm{Pt}$ in $n$-pentane isomerization over $\mathrm{P} / \mathrm{WZ}$ under hydrogen environment is due to the dissociative $\mathrm{H}_{2}$ chemisorption on platinum [9]. The presence of platinum facilitates the reduction of surface $\mathrm{W}^{6+}$, which is important for the isomerization reaction. The promotional effect of iron in the singly promoted $\mathrm{F}_{1.2} \mathrm{WZ}$ catalyst may also be explained by the above redox effect.

To explain how a strong interaction between iron promoter and $\mathrm{WZ}$ can promote the catalytic reaction, we first compared the $\mathrm{W}-\mathrm{O}-\mathrm{W}$ bond distance of bulk $\mathrm{WO}_{3}$ and $\mathrm{WO}_{x}$ in WZ. One can see from the $\mathrm{W}-\mathrm{L}_{\mathrm{II}, \mathrm{III}}-$ edge EXAFS $\mathrm{RDF}$ plots that the $\mathrm{W}-\mathrm{O}-\mathrm{W}$ distance of $\mathrm{WO}_{x}$ (in WZ) is much shorter than that of $\mathrm{WO}_{3}$. Therefore, interaction between $\mathrm{WO}_{x}$ and zirconia can cause severe distortion of $\mathrm{WO}_{x}$ lattice, possibly by changing the $\mathrm{W}-\mathrm{O}-\mathrm{W}$ bond angle. This phenomenon will lead to great strain in $\mathrm{W}-\mathrm{O}-\mathrm{W}$ bond and will increase $\mathrm{WO}_{x}$ reducibility. However, one must not forget the stabilization effect of the zirconia support through $\mathrm{WO}_{x}-\mathrm{ZrO}_{2}$ interaction. We think that the resultant effect of $\mathrm{W}-\mathrm{O}-\mathrm{W}$ bond strain and stabilization by the support in $\mathrm{WO}_{x}$ is to control the degree of its reduction to occur just on the surface layer with the formation of $\mathrm{W}^{5+}$ and Brønsted acid sites at the required temperature range for the isomerization reaction. We can see that the surface of $\mathrm{WO}_{x}$ can be reduced by hydrogen at a temperature as low as $200{ }^{\circ} \mathrm{C}$ [7].

In $\mathrm{F}_{1.2} \mathrm{WZ}$, its $\mathrm{W}-\mathrm{O}-\mathrm{W}$ bond length is even shorter (although slightly) than that of WZ. Here, the iron promoter interacts directly with $\mathrm{WO}_{x}$ with the formation of $\mathrm{W}-\mathrm{O}-\mathrm{Fe}$ linkages. This leads us to suggest that the formation of $\mathrm{W}-\mathrm{O}-\mathrm{Fe}$ linkages helps to optimize the resultant effect mentioned above. It is probable that the peak $\left(\sim 690^{\circ} \mathrm{C}\right)$, which appears before the main reduction peak of $\mathrm{WO}_{x}$ in the TPR profile of $\mathrm{F}_{1.2} \mathrm{WZ}$ is due to this effect. In addition, we have observed EPR signal corresponds to $\mathrm{W}^{5+}$ in the reduction of $\mathrm{F}_{1.2} \mathrm{WZ}$ by hydrogen at $300{ }^{\circ} \mathrm{C}$ (reaction temperature) with $g_{\perp}$ at 1.89 (and maybe $g_{\perp}$ at 1.96) [7].

As the iron promoter is present as highly dispersed species on the surface of $\mathrm{WO}_{x}$ in $\mathrm{F}_{1.2} \mathrm{WZ}$ catalyst (see Section 4.5), a large number of surface $\mathrm{W}-\mathrm{O}-\mathrm{Fe}$ linkages will influence greatly the surface structure of $\mathrm{WO}_{x}$ and made its reduction more effective. If the iron promoter were a bulk species, then any interaction between iron and the surrounding may not have much impact on catalytic performance, since catalysis is a surface phenomenon. 
Another possible function of iron promoter is to act as a redox site for the generation of Brønsted acid site from hydrogen species produced by hydrogen or $n$-butane dissociation:

$\mathrm{Fe}^{3+}+\mathrm{H}^{\bullet} \rightarrow \mathrm{Fe}^{2+}+\mathrm{H}^{+}$

Kuba et al. [7] has suggested that $n$-pentane activation on WZ proceeds via homolytic $\mathrm{C}-\mathrm{H}$ bond cleavage (see Section 1). Under the influence of iron, $n$-butane might do the same thing in $\mathrm{F}_{1.2} \mathrm{WZ}$ and the $n$-butyl radical generated as a consequence of this mechanism can undergo interaction with $\mathrm{Fe}^{3+}$ (see Section 4.4). The presence of $\mathrm{Fe}^{2+}$ is suggested by our TPO results.

In summary, the iron promoter may play multiple roles in $n$-butane isomerization reaction and a clear view requires further study.

\subsection{Cooperative effect of iron and platinum}

In the doubly promoted $\mathrm{P} / \mathrm{F}_{1.2} \mathrm{WZ}$ catalyst, there may be an additional cooperative role of iron promoter besides the one mentioned above. This is because the catalytic performance of this doubly promoted catalyst is much higher than the sum of the corresponding individually promoted catalyst (Table 1 and Fig. 1). The cooperative roles of platinum and iron promoters act in two ways: that is, through platinum-iron interaction and through their close proximity to each other.

We have seen in the TPR results that the low temperature reduction of $\mathrm{WO}_{x}$ in $\mathrm{P} / \mathrm{WZ}$ is suppressed by iron in $\mathrm{P} /$ $\mathrm{F}_{1.2} \mathrm{WZ}$. The hydrogen adsorption and therefore hydrogenolysis capability of platinum may be suppressed by the interaction with iron. As the platinum in $\mathrm{P} / \mathrm{FWZ}$ catalyst normally exists in a highly dispersed state, the suppression of its hydrogenolysis capability would have improved the selectivity of the isomerization product as shown in Table 1 [9]. Otherwise, hydrogenolysis of reactant and product on the highly dispersed platinum may be too serious. Therefore, platinum-iron interaction may help to check the hydrogenolysis effect of the highly dispersed platinum particles so that the selectivity of the isomerized product is not much affected compared to the reference P/WZ. We can see that the isobutane selectivity of our $\mathrm{P} / \mathrm{F}_{1.2} \mathrm{WZ}$ catalyst is still very high, even though it has high catalytic activity.

To explain the exceptionally high activity of $\mathrm{P} / \mathrm{F}_{1.2} \mathrm{WZ}$ catalyst, we suggest that a close proximity of platinum to iron promoters may help the diffusion of the intermediate formed after $n$-butane activation to the acid sites created by platinum. In the study of Lukinskas et al. [9], the iron promoter was also suggested to help the diffusion of activated hydrogenolysis products from platinum to the Brønsted acid sites, leading to improved selectivity of isomers. In our case, the iron promoter may first stabilize the butyl radical produced after $n$-butane activation on $\mathrm{WO}_{x}$ and may form a reservoir of this species. This kind of interaction may involve $\mathrm{F} \mathrm{Fe}^{3+} / \mathrm{Fe}^{2+}$ redox couple, as described by Lukinskas et al. [9]. Dissociation of this radical species will release butene to the acid sites for the generation of $\mathrm{C}_{8}{ }^{+}$(a secondary intermediate well-known for this reaction; see Eqs. (4) and (5)). Obviously, the consumption of butene will promote further activation of $n$-butane and the cycle is repeated. A possible indication of the interaction between butyl radical and iron promoter comes from the selectivity of cracking products in $n$-butane isomerization. We can see that the propane yield increases significantly with iron content and this may indicate the cracking of butyl radical on iron promoter sites with the formation of iron carbide. However, we cannot say unambiguously that the weight loss observed in our TPO profile of the used $\mathrm{P} / \mathrm{F}_{1.2} \mathrm{WZ}$ catalyst is due to the formation of iron carbide. Further study on this problem is needed.

\subsection{Location and nature of iron promoter on fresh $F W Z$}

The promotional effect of platinum and iron mentioned in Sections 4.3 and 4.4 required that they are present on the surface of WZ. Besides, Section 4.2 suggests a strong interaction of iron and WZ. Thus, we also try to locate the site of iron promoter in $\mathrm{F}_{1.2} \mathrm{WZ}$ and to determine its nature. The location of platinum promoter is not discussed in this paper but it is generally shown to be on the surface of WZ [8].

In the study of Yamamoto et al. [16] regarding ironpromoted sulfated zirconia (FMSZ) catalysts, they found in their Fe-K-edge EXAFS RDF plot a peak due to oxygen neighbors at around $1.6 \AA$, and another peak at $3.3 \AA$ due to zirconium neighbors. No peak due to iron neighbors was observed. Yamamoto et al. [16] finally concluded that the iron promoter is dispersed in the bulk of the zirconia, and that the iron atom does not participate directly in $n$-butane isomerization reaction. In our study on $\mathrm{F}_{1.2} \mathrm{WZ}$ catalysts, the iron promoter was impregnated onto the surface of the hydroxide of $\mathrm{WZ}$ and not on the surface of zirconium hydroxide as in the case of FMSZ. Therefore, we suggest that the iron promoter of our $\mathrm{F}_{1.2} \mathrm{WZ}$ catalyst is found on the surface of $\mathrm{WZ}$ and not in the bulk of zirconia. We provide three supporting arguments for our proposition, as listed below:

(i) A new peak was observed at nearly $4 \AA$ in our $\mathrm{F}_{1.2} \mathrm{WZ}$

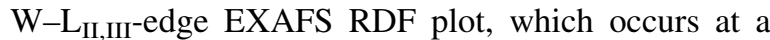
bond distance much longer than that for $\mathrm{W}-\mathrm{O}-\mathrm{W}$. It could only be due to a terminal bonded iron species on $\mathrm{WO}_{x}$ of $\mathrm{WZ}(\mathrm{W}-\mathrm{O}-\mathrm{Fe})$. A terminal bonded $\mathrm{Al}^{3+}$ species on WZ was also observed at a similar bond distance [13]. Besides, there is no indication of iron substitution into the $\mathrm{WO}_{x}$ structure of $\mathrm{F}_{1.2} \mathrm{WZ}$ catalyst, since no broadening of $\mathrm{W}-\mathrm{O}-\mathrm{W}$ peak was observed relative to that of $\mathrm{WZ}$. In addition, this iron species should remain on the surface under the reaction condition, since $300{ }^{\circ} \mathrm{C}$ is too low for iron dissolution into the bulk structure. 
(ii) The addition of iron promoter on $\mathrm{WZ}$ increases the molar yield of propane in the cracking product. This catalytic result further strengthens the idea that the iron promoter is a surface and not a bulk species. The TPO result seems to indicate the reduction of $\mathrm{Fe}^{3+}$ to $\mathrm{Fe}^{2+}$ and it can be re-oxidized by air, as shown by the weight gain in $\mathrm{P} / \mathrm{F}_{1.2} \mathrm{WZ}$ catalyst at temperature beyond $500{ }^{\circ} \mathrm{C}$

(iii) The iron promoter is sensitive to surface chemisorbed water as revealed by the activity jump from first (with fresh catalyst) to second (with regenerated catalyst) catalytic cycle. Higher activity is recorded for regenerated catalyst, since it has been subjected to higher temperature $\left(450{ }^{\circ} \mathrm{C}\right.$ during catalyst regeneration) prior to reaction as compared to the fresh catalyst $\left(300{ }^{\circ} \mathrm{C}\right.$ during catalyst pretreatment); hence, less chemisorbed water is present on the catalyst surface of this catalyst before the reaction starts. In fact, a fresh catalyst pretreated at $450{ }^{\circ} \mathrm{C}$ gave similar activity to that of the regenerated catalyst mentioned here. The much higher activity jump observed in $\mathrm{F}_{1.2} \mathrm{WZ}$ relative to $\mathrm{WZ}$ indicates poisoning of the iron promoter by chemisorbed water. One can see that the second and third catalytic cycles where they were subjected to the same catalyst regeneration temperature gave similar activity profiles and this confirms our previous suggestion. A detailed account of this phenomenon has been published in a separate paper [13].

Evidently, the presence of tungsten species on zirconium hydroxide can influence the distribution of iron species in the calcined product and cause results different from that of pure zirconium hydroxide. We suggest that iron promoter is mainly exposed on the surface of $\mathrm{WZ}$ in $\mathrm{F}_{1.2} \mathrm{WZ}$, whereas it is dispersed in the bulk of zirconia in FMSZ [16].

It is possible that most of the iron species reside at the surface vacant sites of zirconia in $\mathrm{F}_{1.2} \mathrm{WZ}$, similar to the case of Carrier et al. [18]. Probably, our Zr-K-edge EXAFS spectra do not show peak broadening since only the surface layer of zirconia is affected. The observed EPR signal at a $g$ value of about 4.26 can be assigned to this isolated $\mathrm{Fe}^{3+}$ in $\mathrm{Fe}-\mathrm{O}-\mathrm{Zr}$ (and also $\mathrm{Fe}-\mathrm{O}-\mathrm{W}$ ) [28]. Fine $\alpha-\mathrm{Fe}_{2} \mathrm{O}_{3}$-like clusters are also observed with a $g$-value at about 2.04 [28]. By comparing the EPR results, one can also see that our $\mathrm{F}_{1.2} \mathrm{WZ}$ catalyst has more iron in $\alpha-\mathrm{Fe}_{2} \mathrm{O}_{3}$ (relative to isolated $\mathrm{Fe}^{3+}$ ) than the catalysts prepared by Carrier et al. [18]. This discrepancy can be explained by our different methods of catalyst preparation. The reduction peak at $421{ }^{\circ} \mathrm{C}$ in the TPR profile of $\mathrm{F}_{1.2} \mathrm{WZ}$ is thus attributed to the consumption of hydrogen by the oxo-bridge of $\mathrm{Fe}-\mathrm{O}-\mathrm{Fe}$ in $\mathrm{Fe}_{2} \mathrm{O}_{3}$. We also note that the proportion of isolated $\mathrm{Fe}^{3+}$ species can be increased by a redispersion (reduction/ oxidation) process.

XANES and EXAFS techniques can give us a rather clear picture of the nature of iron promoter in our fresh $\mathrm{F}_{1.2} \mathrm{WZ}$ catalyst. XANES can provide information on the oxidation state of the central absorbing iron atom. XANES of the $\mathrm{Fe}$ $1 \mathrm{~s} \rightarrow 4 \mathrm{p}$ transition indicates that the iron promoter in $\mathrm{F}_{1.2} \mathrm{WZ}$ exists as $\mathrm{Fe}^{3+}$ species. EXAFS can provide direct information on the local environment of the central absorbing iron atom. In the case of $\mathrm{F}_{1.2} \mathrm{WZ}$, it is obvious from the low intensity of the RDF peaks assigned to $\alpha-\mathrm{Fe}_{2} \mathrm{O}_{3}$ ( $\mathrm{Fe}-\mathrm{O}-\mathrm{Fe}$ at $2.67 \AA)$ and the presence of isolated $\mathrm{Fe}^{3+}$ species ( $\mathrm{Fe}-\mathrm{O}-\mathrm{Zr}$ at $3.3 \AA$ and $\mathrm{Fe}-\mathrm{O}-\mathrm{W}$ at $\sim 4 \AA$ ) that the iron promoter exists in a highly dispersed state and this is consistent with our EPR results.

In summary, the iron promoter of our fresh $\mathrm{F}_{1.2} \mathrm{WZ}$ catalyst may exist in three different forms: fine $\alpha-\mathrm{Fe}_{2} \mathrm{O}_{3}$-like clusters $(\mathrm{Fe}-\mathrm{O}-\mathrm{Fe}), \mathrm{Fe}^{3+}$ at surface vacant sites of zirconia $(\mathrm{Fe}-\mathrm{O}-\mathrm{Zr})$, and terminal bonded $\mathrm{Fe}^{3+}$ on $\mathrm{WO}_{x}(\mathrm{Fe}-\mathrm{O}-\mathrm{W})$. The question of how these species transformed during the pretreatment and catalytic conditions is a subject of further study.

\section{Conclusion}

We have investigated the promotional effect of iron in $\mathrm{F}_{1.2} \mathrm{WZ}$ and $\mathrm{P} / \mathrm{F}_{1.2} \mathrm{WZ}$ catalysts for $n$-butane isomerization reaction. We focused on the location and function of the iron species in both the singly and doubly promoted catalyst systems and then correlated to the catalytic results. The important characterization and catalytic results over these catalysts are summarized below.

Firstly, the iron promoter in $\mathrm{F}_{1.2} \mathrm{WZ}$ catalyst is situated on the surface and not in the bulk. We have provided three pieces of supporting evidence: that is, terminal bonded iron species are present on $\mathrm{WO}_{x}$ of $\mathrm{F}_{1.2} \mathrm{WZ}(\mathrm{W}-\mathrm{O}-\mathrm{Fe})$; the iron promoter influences the propane ratio in the cracking product; and the iron promoter is poisoned by surface chemisorbed water. XANES, EXAFS, and EPR results suggest that the iron promoter probably exists as a mixture of $\mathrm{Fe}^{3+}$ species such as $\alpha-\mathrm{Fe}_{2} \mathrm{O}_{3}$, isolated $\mathrm{Fe}^{3+}$ anchored on $\mathrm{WO}_{x}$ surface, and $\mathrm{Fe}^{3+}$ situated at surface vacant sites of zirconia.

Secondly, these highly dispersed $\mathrm{Fe}^{3+}$ species in $\mathrm{F}_{1.2} \mathrm{WZ}$ catalyst probably promote $n$-butane isomerization reaction through a redox effect for the generation of Brønsted acid sites. The formation of $\mathrm{W}-\mathrm{O}-\mathrm{Fe}$ linkages causes structural distortion of $\mathrm{WO}_{x}$ surface and facilitates its reduction and formation of Brønsted acid sites. $\mathrm{Fe}^{3+}$ itself can also act as a redox site for the generation of Brønsted acid site from hydrogen species produced by the dissociation of hydrogen or $n$-butane.

Lastly, an additional cooperative role of iron promoter is observed in the doubly promoted $\mathrm{P} / \mathrm{F}_{1.2} \mathrm{WZ}$ catalyst. The close proximity of iron and platinum promoters on $\mathrm{P} / \mathrm{F}_{1.2} \mathrm{WZ}$ catalyst is revealed by TPR and this proximity facilitates the diffusion of intermediate stabilized by iron to the acid sites created by platinum. The ease of migration of species 
between platinum and iron promoters leads to an exceptionally active $\mathrm{P} / \mathrm{F}_{1.2} \mathrm{WZ}$ catalyst.

\section{Acknowledgements}

We are grateful for the financial support of National Science Council of Taiwan through Program for Promoting Academic Excellence of Universities. We would also like to thank MEL company for providing the tungstated zirconia precursors.

\section{References}

[1] M. Hino, K. Arata, J. Chem. Soc., Chem. Commun. (1988) 1259.

[2] J.C. Yori, C.L. Pieck, J.M. Parera, Appl. Catal. 181 (1999) 5.

[3] M. Scheithauer, T.K. Cheung, R.E. Jentoft, R.K. Grasselli, B.C. Gates, H. Knözinger, J. Catal. 180 (1998) 1.

[4] J.C. Vartuli, J.G. Santiesteban, P. Traverso, N. Cardona-Martinéz, C.D. Chang, S.A. Stevenson, J. Catal. 187 (1999) 131.

[5] S.R. Vaudagna, S.A. Canavese, R.A. Comelli, N.S. Fígoli, Appl. Catal. 168 (1998) 93.

[6] S.R. Vaudagna, R.A. Comelli, N.S. Fígoli, Appl. Catal. 164 (1997) 265.

[7] S. Kuba, P.C. Heydorn, R.K. Grasselli, B.C. Gates, M. Che, H. Knözinger, Phys. Chem. Chem. Phys. 3 (2001) 146.

[8] D.G. Barton, S.L. Soled, G.D. Meitzner, G.A. Fuentes, E. Iglesia, J. Catal. 181 (1999) 57.

[9] P. Lukinskas, S. Kuba, B. Spliethoff, R.K. Grasselli, B. Tesche, H. Knozinger, Top. Catal. 23 (2003) 163.

[10] S. Kuba, P. Lukinskas, R.K. Grasselli, B.C. Gates, H. Knozinger, J. Catal. 216 (2003) 353.
[11] X.R. Chen, C.L. Chen, N.P. Xu, C.Y. Mou, Catal. Today 93-5 (2004) 129.

[12] X.R. Chen, C.L. Chen, N.P. Xu, S. Han, C.Y. Mou, Catal. Lett. 85 (2003) 177.

[13] S.T. Wong, T. Li, S. Cheng, J.F. Lee, C.Y. Mou, J. Catal. 215 (2003) 45.

[14] M. Scheithauer, R.E. Jentoft, B.C. Gates, H. Knözinger, J. Catal. 191 (2000) 271.

[15] J.E. Tábora, R.J. Davis, J. Chem. Soc., Faraday Trans. 91 (1995) 1825.

[16] T. Yamamoto, T. Tanaka, S. Takenaka, S. Yoshida, T. Onari, Y. Takahashi, T. Kosaka, S. Hasegawa, M. Kudo, J. Phys. Chem. B 103 (1999) 2385.

[17] Y. Okamoto, T. Kubota, Y. Ohto, S. Nasu, J. Phys. Chem. B 104 (2000) 8462.

[18] X. Carrier, P. Lukinskas, S. Kuba, L. Stievano, F.E. Wagner, M. Che, H. Knözinger, Chem. Phys. Chem. 5 (2004) 1191.

[19] S.T. Wong, J.F. Lee, S. Cheng, C.Y. Mou, Appl. Catal. 198 (2000) 115.

[20] C.D. Baertsch, S.L. Soled, E. Iglesia, J. Phys. Chem. B 105 (2001) 1320.

[21] J.G. Santiesteban, D.C. Calabro, W.S. Borghard, C.D. Chang, J.C. Vartuli, Y.P. Tsao, M.A. Natal-Santiago, R.D. Bastian, J. Catal. 183 (1999) 314.

[22] J.S. Jang, H.G. Kim, V.R. Reddy, S.W. Bae, S.M. Ji, J.S. Lee, J. Catal. 231 (2005) 213.

[23] P. Marturano, L. Drozdová, A. Kogelbauer, R. Prins, J. Catal. 192 (2000) 236.

[24] L.A. Lugovskaya, L.A. Aleshina, G.M. Kalibaeva, A.D. Fofanov, Acta Cryst. B 58 (2002) 576.

[25] Z. Hong, K.B. Fogash, R.M. Watwe, B. Kim, B.I. Masqueda-Jimenez, M.A. Natal-Santiago, J.M. Hill, J.A. Dumesic, J. Catal. 178 (1998) 489.

[26] M.R. Guisnet, Acc. Chem. Res. 23 (1990) 392.

[27] G. Larsen, E. Lotero, S. Raghavan, R.D. Parra, C.A. Querini, Appl. Catal. 139 (1996) 201.

[28] F.C. Jentoft, A. Hahn, J. Kröhnert, G. Lorenz, R.E. Jentoft, T. Ressler, U. Wild, R. Schlögl, C. Häßner, K. Köhler, J. Catal. 224 (2004) 124. 